\section{Root System Distribution Influences Substrate Moisture Measurements in Containerized Ornamental Tree Species}

\author{
Taryn L. Bauerle ${ }^{1,4}$, William L. Bauerle ${ }^{2}$, Marc Goebel $^{3}$, and David \\ M. Barnard ${ }^{2}$
}

AdDITIONAL INDEX WORDs. container production, root development, soil moisture sensors

SUMMARY. Substrate moisture sensors offer an affordable monitoring system for containerized tree production. However, root system distribution can vary greatly among species within ornamental container production systems, resulting in variation within substrate readings among sensors within a container. The aim of this study was to examine the relationship of substrate moisture sensor readings in six ornamental trees to their root distribution patterns within a container. Following root anatomical analysis, tree root systems were dissected by root order as a means to separate fine (uptake) roots and coarse (transport) roots. Substrate moisture variability was measured through the deployment of 12 substrate moisture sensors per container. Of the tree species studied, we found the following two patterns of root distribution: a shallow, "conical-shaped," root system, with the broadest portion of the root system in the shallow soil layer, and a more evenly distributed "cylindrical-shaped" root system. Root system distribution type influenced substrate moisture reading variability. Conical root systems had lower substrate moisture variability and high fine root variability, whereas the opposite was true for cylindrical root systems-most likely due to the larger, coarse woody mass of roots. We were unable to find any correlations between fine root morphological features including root diameter, length, or surface area and substrate moisture variability. However, higher specific root length was associated with higher substrate moisture variability. Classifying a tree's root system by its growth and distribution within a container can account for variation in substrate moisture readings and help inform future decisions on sensor placement within containerized systems.

$\mathrm{I}$ ncreasing irrigation efficiency is an important component of optimizing water use in containerized nursery operations. Grouping plants by water use requirements and using appropriate irrigation systems can aid in reducing container leachate (Bilderback, 2002). However, containerized plants have a limited substrate volume, often times requiring several irrigation events per day.

This paper is part of a series of manuscripts describing the research and development completed by the SCRI-MINDS (Managing Irrigation and Nutrition through Distributed Sensing) project. The authors gratefully acknowledge funding and support from the USDA-NIFA Specialty Crops Research Initiative; Award \#2009-51181-05768.

We thank the members of the Bauerle laboratory for their help in dissecting root systems.

${ }^{1}$ Department of Horticulture, Cornell University, 134A Plant Science Building, Ithaca, NY 14853

${ }^{2}$ Department of Horticulture \& Landscape Architecture, 213 Shepardson Building, 1173 Campus Delivery, Colorado State University, Fort Collins, CO 80523

${ }^{3}$ Intercollege Program in Ecology, The Pennsylvania State University, University Park, PA 16802

${ }^{4}$ Corresponding author. E-mail: bauerle@cornell.edu.
Moreover, variability in substrate moisture within a container can be substantial, making characterization of available moisture for root uptake a challenge (Daniels et al., 2012). Given that water uptake by plant roots is the primary driver of soil moisture depletion in irrigated crop production systems (Clothier and Green, 1994), surprisingly few studies report how root system development affects water extraction patterns (Andreu et al., 1997; Coelho and Or, 1999; Daniels et al., 2012). Consequently, the influence of root development on containerized substrate moisture variation, which is known to influence root water uptake, is insufficiently described to inform irrigation applications (Beeson, 2007; Cannavo and Michel, 2013).

Not all root systems have the same architecture or are equally distributed throughout the soil profile (Fitter, 1987; Hodge et al., 2009). For example, numerous studies have examined root distribution in response to irrigation in field-grown crops (Andreu et al., 1997; Coelho and Or, 1999; Yu et al., 2007), concluding that it is common for root density to decrease with soil depth (Passioura, 2002). Recently, total root distribution, expressed as root biomass, has been shown to affect substrate heterogeneity and the retention of water within soilless container substrates (Cannavo and Michel, 2013). However, measuring root biomass alone does not take into account the changes in root foraging ability (Hodge, 2004). Root exploration within the soil volume is largely dictated by root systems architecture, including variables such as root length, depth, lateral root expansion, and branching (Hodge et al., 2009). Nonetheless, the perennial growth habit and sampling difficulties have resulted in few studies that investigate root distribution changes in containerized woody plant species.

The substrate moisture and root system matrix within containers is a heterogeneous volume that provides a means to compare species differences in root morphology. The objective of this study was to examine the relationship between root occupation within the soil volume and soil moisture sensor variability. We hypothesized that high variability in fine root density will result in high sensor variability. Additionally, we predicted

\begin{tabular}{llll}
\hline $\begin{array}{l}\text { Units } \\
\text { To convert U.S. to SI, } \\
\text { multiply by }\end{array}$ & U.S. unit & SI unit & $\begin{array}{l}\text { To convert SI to U.S., } \\
\text { multiply by }\end{array}$ \\
\hline 29.5735 & $\mathrm{fl} \mathrm{oz}$ & $\mathrm{mL}$ & 0.0338 \\
0.3048 & $\mathrm{ft}$ & $\mathrm{m}$ & 3.2808 \\
3.7854 & gal & $\mathrm{L}$ & 0.2642 \\
2.54 & inch $(\mathrm{es})$ & $\mathrm{cm}$ & 0.3937 \\
25.4 & inch $(\mathrm{es})$ & $\mathrm{mm}$ & 0.0394 \\
6.4516 & inch & $\mathrm{cm}^{2}$ & 0.1550 \\
0.0896 & inch/oz & $\mathrm{cm} \cdot \mathrm{g}^{-1}$ & 11.1612 \\
28.3495 & $\mathrm{oz}$ & $\mathrm{g}$ & 0.0353 \\
$\left({ }^{\circ} \mathrm{F}-32\right) \div 1.8$ & ${ }^{\circ} \mathrm{F}$ & ${ }^{\circ} \mathrm{C}$ & $\left({ }^{\circ} \mathrm{C} \times 1.8\right)+32$
\end{tabular}


that species with a high proportion of course roots would result in high sensor variability due to displacement of soil and water by the disproportionate large root mass. Understanding the effects of root growth and developmental patterns will have clear implications on how we water, fertilize, and manage our trees.

\section{Materials and methods}

Plant material. The following six nursery tree species with varying root growth strategies were selected for this study: red maple (Acer rubrum 'Franksred'), honey locust (Gletitsia triacanthos var. intermis 'Skycole'), red oak (Quercus rubra 'Rubrum'), hornbeam (Carpinus betula 'Columnaris'), redbud (Cercis canadensis), and birch (Betula nigra 'Cully'). Five replicates of 2-year-old liners per species were transplanted in Apr. 2010 into 15 -gal pots $(44 \mathrm{~cm}$ wide $\times 38 \mathrm{~cm}$ deep) containing a mixture of $64 \%$ pine bark, $21 \%$ peatmoss, $7 \%$ sterilized reground potting soil, 7\% Haydite (Type B; DiGeronimo Aggregates, Independence, $\mathrm{OH}$ ), and $1 \%$ slowrelease $12 \mathrm{~N}-0 \mathrm{P}-34.9 \mathrm{~K}$ fertilizer (Agrozz, Wooster, OH). Trees were arranged in a randomized block design and grown $1.6 \mathrm{~m}$ on center in a pot-in-pot system at the Colorado State University Horticulture Field Research Laboratory, Fort Collins, CO. Controlled-release $18 \mathrm{~N}-2.2 \mathrm{P}-$ $7.5 \mathrm{~K}$ fertilizer was topdressed one time during each season (Osmocote Classic; Scotts, Marysville, OH). Tree containers were irrigated on a timer using one $360^{\circ}$ spray stake per pot positioned $\approx 2$ inches from the tree stem to maintain a volumetric water content (VWC) between 35\% and $42 \%$, verified weekly with a handheld soil moisture sensor (ThetaProbe; Dynamax, Houston, TX).

SubStrate SOIL MOISTURE MEASUREMENTS. To characterize within-layer variation in substrate moisture, we deployed an array of 12 capacitance/frequency-domain sensors (model 5TM; Decagon Devices, Pullman, WA) with a $1-\mathrm{L}$ field of measurement in one container of each of the six species. Sensors were inserted 6 inches into the container through a hole drilled in the container wall. Holes were covered with duct tape to prevent preferential flow paths. The sensors were arranged in a matrix of three vertical layers $(10,20$, and
$30 \mathrm{~cm}$ below the substrate surface) with four sensors in each layer (one sensor in each of the four cardinal directions). Sensors were connected to wireless data loggers (model EM50R, Decagon Devices) that read sensor output once every minute from which a 5-min average was recorded. Raw sensor output (millivolts) was then averaged over the four sensors within each layer and converted to VWC via a calibration equation developed specifically for this substratesensor combination. Variance measurements were calculated on a layer basis as the average of the four sensors per layer.

Root HARVESTS. Three replicate trees of each species were randomly selected and destructively harvested in July 2010. The stem was first separated from the root collar with a fine tooth saw and then we separated the container into three equal volumes by depth (about $10 \mathrm{~cm}$ thick), dividing each layer into nine equal sections for a total of $27 \mathrm{sec}$ tions per container. Two random root segment samples, one from a quadrate located in the interior portion of the container and one from an exterior quadrate were carefully excavated from each soil layer and immediately wrapped in damp paper towels and refrigerated. The roots in the remaining sections were gently washed free of adhering soil and brought back to the laboratory for analysis. Three replicates of $10-\mathrm{cm}$-long segments of each tree species were fixed in FAA (5 mL formaldehyde, $5 \mathrm{~mL}$ acetic acid, and $90 \mathrm{~mL}$ of $70 \%$ ethanol) solution and dissected by root order (Berntson, 1997; Fitter, 1987; Guo et al., 2008) following Strahler's stream ordering system (Pregitzer, 2002 ) such that roots ending in a tip were classified as first order; two firstorder roots join a second-order root; two second-order roots join a thirdorder root, and so on. This classification recognizes a shift in function from fine roots (roots with primary anatomical development that are responsible for water uptake) to coarse roots (roots responsible for transport and anchorage) that occur with increasing root order (Pregitzer, 2002). Root segments were fresh sectioned and imaged under light microscope (Axioskop II; Zeiss, Jena, Germany) at $20 \times$ magnification. Cross-sections were used to determine the anatomical development of root orders of each species with the presence or absence of a periderm and indications of secondary development. Based on these findings, subsequent root biomass in the harvested sections were separated by appropriate species-specific root orders that represented fine roots of primary anatomical development (uptake) roots (red maple, orders 1-2; honey locust, order 1; birch, orders 1-2; redbud, orders 1-2; hornbeam, orders 1-3; red oak, orders 1-3) vs. coarse (transport) development as a means of identifying root function.

Root scans. Intact 5-cm-long branching root modules of each species root system were scanned on a modified flatbed scanner (Expressions 10000XL; Epson, Nagon, Japan) and classified by root branching order (Fitter, 1987). Subsequent image files were analyzed with Winrhizo Pro (version 2007d; Regents Instruments, Victoria, BC, Canada) for morphological analysis by root order, including root diameter (millimeters), surface area (square centimeters), and length (centimeters). Samples were then dried for $48 \mathrm{~h}$ at $70{ }^{\circ} \mathrm{C}$, and root weight was used to calculate specific root length [SRL (centimeter per gram)].

Data analysis. Average total root biomass was calculated by depth $(0-10 \mathrm{~cm}, 10-20 \mathrm{~cm}$, and $20-30 \mathrm{~cm})$ for each species. Data were analyzed using Kruskal-Wallis nonparametric analysis of variance (ANOVA) and standard errors were calculated. We linearly regressed fine and coarse root biomass variation to $\mathrm{VWC}$ variation.

Root morphology data were then examined for species differences in root length and diameter and surface area of fine root tips (only first-order roots) (ANOVA). Root morphological parameters and calculated root SRL of the sampled $5-\mathrm{cm}$ root branches were then also linearly regressed with substrate VWC variability. All analysis was performed in JMP pro (version 9.0; SAS Institute, Cary, NC).

\section{Results}

Root BIOmass. Total root biomass results indicated two strategies for root placement within the container $(P=0.002)$; thus, species were parsed into two root system classifications, those having a "conical" (red maple, birch, hornbeam) shaped root distribution, in which a large portion of the total root biomass was within 
the top $10 \mathrm{~cm}$ of the container and those with a "cylindrical" shaped root distribution (redbud, honey locust, and red oak) where total root biomass was high in the top $(0-10 \mathrm{~cm})$ and middle $(10-20 \mathrm{~cm})$ portions of the container (Fig. 1). Red oak, honey locust, and redbud root systems also had higher average coarse root biomass within the central depth
$(10-20 \mathrm{~cm})$ of the container than the other three species $(P \leq 0.001)$.

Examination of the fine root population responsible for the majority of water uptake for the species between conical- and cylindricalrooted species, by specific anatomical root order classifications, showed consistently opposite relationships between the variation in soil moisture
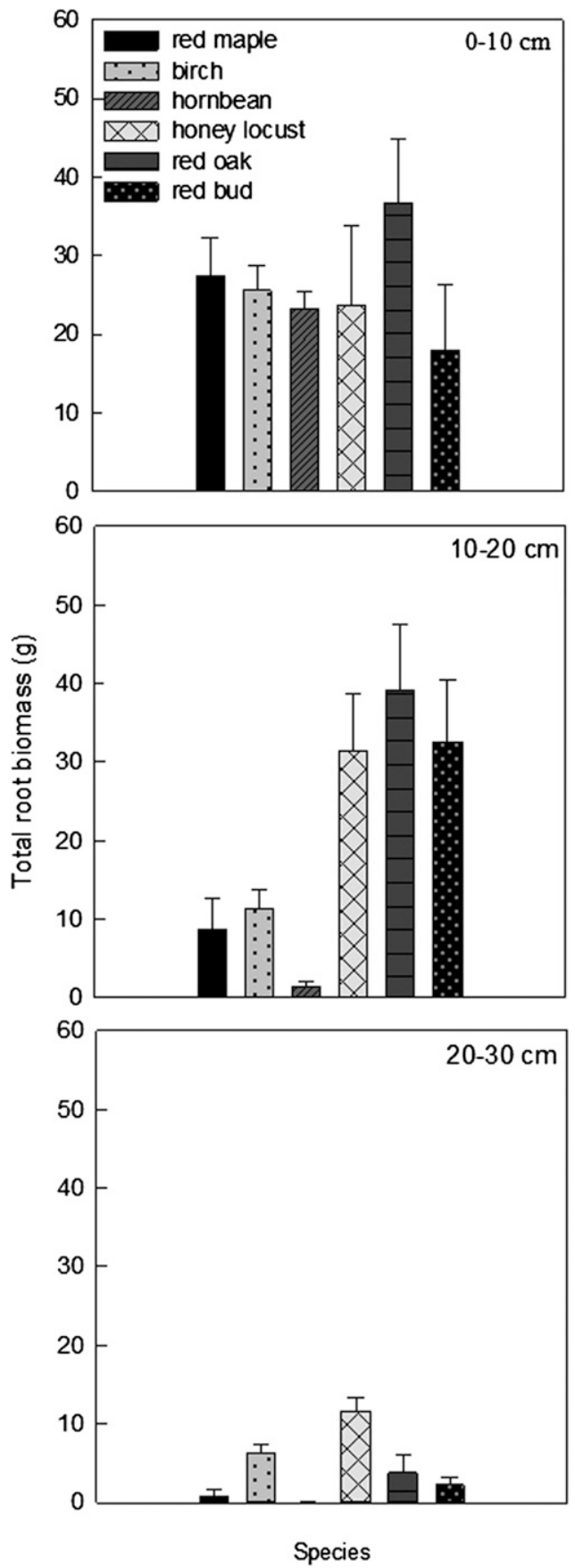

Fig. 1. Average total root biomass for 2-year-old liners of six ornamental tree species (red maple, honey locust, red oak, birch, redbud, and hornbeam) over three soil depths $(01-10,10-20$, and $20-30 \mathrm{~cm})$, growing in 15-gal $(56.8 \mathrm{~L})$ containers; $1 \mathrm{~cm}=0.3937$ inch, $1 \mathrm{~g}=0.0353 \mathrm{oz}$.

sensor readings over the three depths of the container to the variation in the placement of fine roots $(P \leq 0.001)$ (Fig. 2). Species with a conical root distribution showed an unexpected decrease in the $\mathrm{CV}$ of the soil moisture sensor readings with an increase in fine root variability overall three substrate depths, although a significant relationship was only found in $0-10 \mathrm{~cm}$ $\left(P=0.039, R^{2}=0.99\right)$ and $10-20 \mathrm{~cm}$ $\left(P=0.048, R^{2}=0.99\right)$. For the conical distribution, the shallowest substrate depth $(0-10 \mathrm{~cm})$ had the highest proportion of fine roots and also the highest variation in soil moisture, which was associated with relatively high variation in fine root weight $(>80 \%)$ (Fig. 2A). Species classified as having cylindrical root systems, on the other hand, did not show a significant relationship between fine root mass distribution and substrate moisture variability for the top $(0-10 \mathrm{~cm})$ $\left(P=0.143, R^{2}=0.95\right)$ and middle $(10-20 \mathrm{~cm})$ substrate layers $(P=$ $0.123, R^{2}=0.96$ ), or the deepest $(20-30 \mathrm{~cm})$ portion of the container $\left(P=0.725, R^{2}=0.17\right)$ (Fig. 2).

In some instances, there was a significant difference between the substrate layers within the container for the large mass of coarse roots of conical and cylindrical root systems. We did not find a difference in coarse root biomass within the top portion of the container $(P=0.80)$, but significant differences were found at the $10-20 \mathrm{~cm}(P \leq 0.001)$ and $20-30$ $\mathrm{cm}(P=0.05)$ depths between root system types. However, we were unable to find a tight correlation between the square or triangle root distribution variation and substrate moisture variability at any depth, perhaps because of the high substrate moisture variability found within redbud (Fig. 2).

ROOT MORPHOLOGY. Root branch segments used for scanning were standardized by length. To standardize across species, we examined the finest first-order roots within the root scan for each species. Not surprisingly, species differed in their diameter $(P \leq 0.001)$ and length $(P \leq$ $0.001)$ and surface area $(P \leq 0.001)$ (Table 1). However, we were unable to find any correlation between root diameter, root length, or root surface area and substrate moisture variability with depth for the two contrasting root types. Specific root length was 

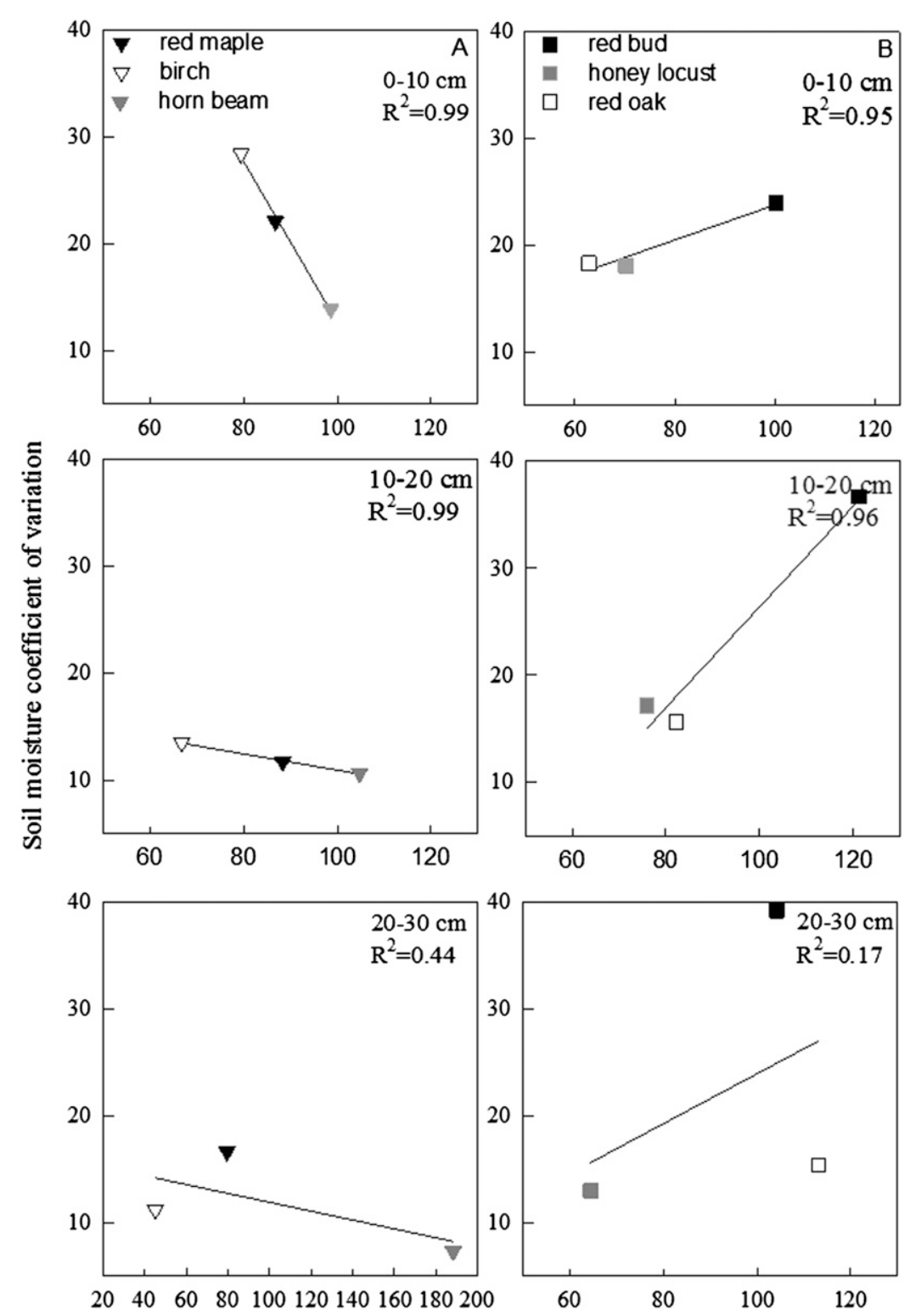

Fine roots coefficient of variation

Fig. 2. The relationship of the $\mathrm{CV}$ for volumetric substrate water content in July 2010 to the $\mathrm{CV}$ in fine roots with primary development for species with (A) a conical root distribution within a 15 -gal $(56.8 \mathrm{~L})$ container (red maple, birch, and hornbeam) and (B) a cylindrical root distribution (red oak, honey locust, and redbud) over three container depths $(0-10,10-20$, and $20-30 \mathrm{~cm})(n=3$ replicates per tree species); $1 \mathrm{~cm}=0.3937$ inch.

also different among species $(P \leq$ $0.001)$, with a positive trend between SRL and soil moisture variability within the center depth of the container $(10-20 \mathrm{~cm}),\left(P=0.082, R^{2}=\right.$ $0.57)$. Although not significant, this suggests that as SRL increases, so does the variability in substrate moisture readings (Fig. 3).

\section{Discussion}

Most commonly, root system distribution is examined as a measure of root biomass distribution. This is the first study to examine the variability in substrate moisture sensor readings that arises from root distribution and function among containerized tree species. Our data show a clear distinction into two major root distribution types among six ornamental tree species, suggesting root water uptake potential varies between conical and cylindrical root systems. Red maple, birch, and hornbeam show conical root distribution, largely accessing the shallower portions of the container and red oak, honey locust, and redbud demonstrate cylindrical root distribution-accessing a larger portion of the shallower and central layers of the container (Fig. 1). Interestingly, these results go against the common assumption that the site of highest root density is located at the container bottom as a root system develops. We were only able to find one other study on root distribution within a containerized ornamental system, rose [Rosa (Cannavo and Michel, 2013)]. Although this study supported the notion of more root growth in the deeper layers of the container, the containers in that study were only $10 \mathrm{~cm}$ deep and the root systems were only quantified on a biomass basis. It is important to note that fine roots serve multiple functions, with a shift in function from absorption and uptake, at a primary anatomical development stage, to transport and anchorage occurring with fine root maturation (Hao et al., 2005; Pregitzer, 2002; Yu et al., 2007). Although it is not surprising that we found species differences in the number of fine root orders responsible for water uptake, it is interesting that we found two distinct relationships between fine root distribution variability and substrate moisture variability. Thus, for the species that show a conical tree root system, higher substrate moisture variability was present where the majority of their roots were located $[0-10 \mathrm{~cm}$ (Fig. 2)]. This creates a conundrum because it may be that sensor placement in the densest area of the root system provides the most realistic substrate moisture values, but it also results in higher variability among the substrate moisture readings. We note that data from tree root systems that followed a more square distribution should be interpreted with caution in that the high substrate moisture and fine root distribution variability found within one species, redbud, created a positive relationship between moisture and root variability.

Morphological traits of fine root systems can help describe root growth strategies, including water and nutrient uptake (Comas et al., 2002). Among species, we found differences in root system morphological traitsincluding root diameter, length and surface area. These differences, however, were not always consistent between the conical and cylindrical root 
Table 1. Root morphological characteristics, including mean root diameter, root length, and root surface area of the first-order roots for six ornamental tree species.

\begin{tabular}{lcccccc}
\hline Species & $\begin{array}{c}\text { Mean root } \\
\text { diam }(\mathbf{m m})^{\mathrm{z}}\end{array}$ & $\begin{array}{c}\text { SE } \\
\text { length }(\mathbf{c m})^{\mathrm{z}}\end{array}$ & $\begin{array}{c}\text { SE } \\
\text { lean root }\end{array}$ & $\begin{array}{c}\text { Mean } \\
\text { area }\left(\mathbf{c m}^{2}\right)^{\mathrm{z}}\end{array}$ & SE \\
\hline Red maple & 0.371 & 0.035 & 0.310 & 0.028 & 0.088 & 0.035 \\
Hornbeam & 0.189 & 0.020 & 0.504 & 0.084 & 0.080 & 0.046 \\
Honey locust & 0.194 & 0.008 & 0.164 & 0.028 & 0.115 & 0.044 \\
Red oak & 0.321 & 0.015 & 0.456 & 0.023 & 0.095 & 0.052 \\
Birch & 0.189 & 0.020 & 0.114 & 0.011 & 0.090 & 0.047 \\
Redbud & 0.182 & 0.033 & 0.079 & 0.007 & 0.096 & 0.048 \\
\hline
\end{tabular}

${ }^{2} 1 \mathrm{~mm}=0.0394$ inch, $1 \mathrm{~cm}=0.3937$ inch, $1 \mathrm{~cm}^{2}=0.1550$ inch $^{2}$.

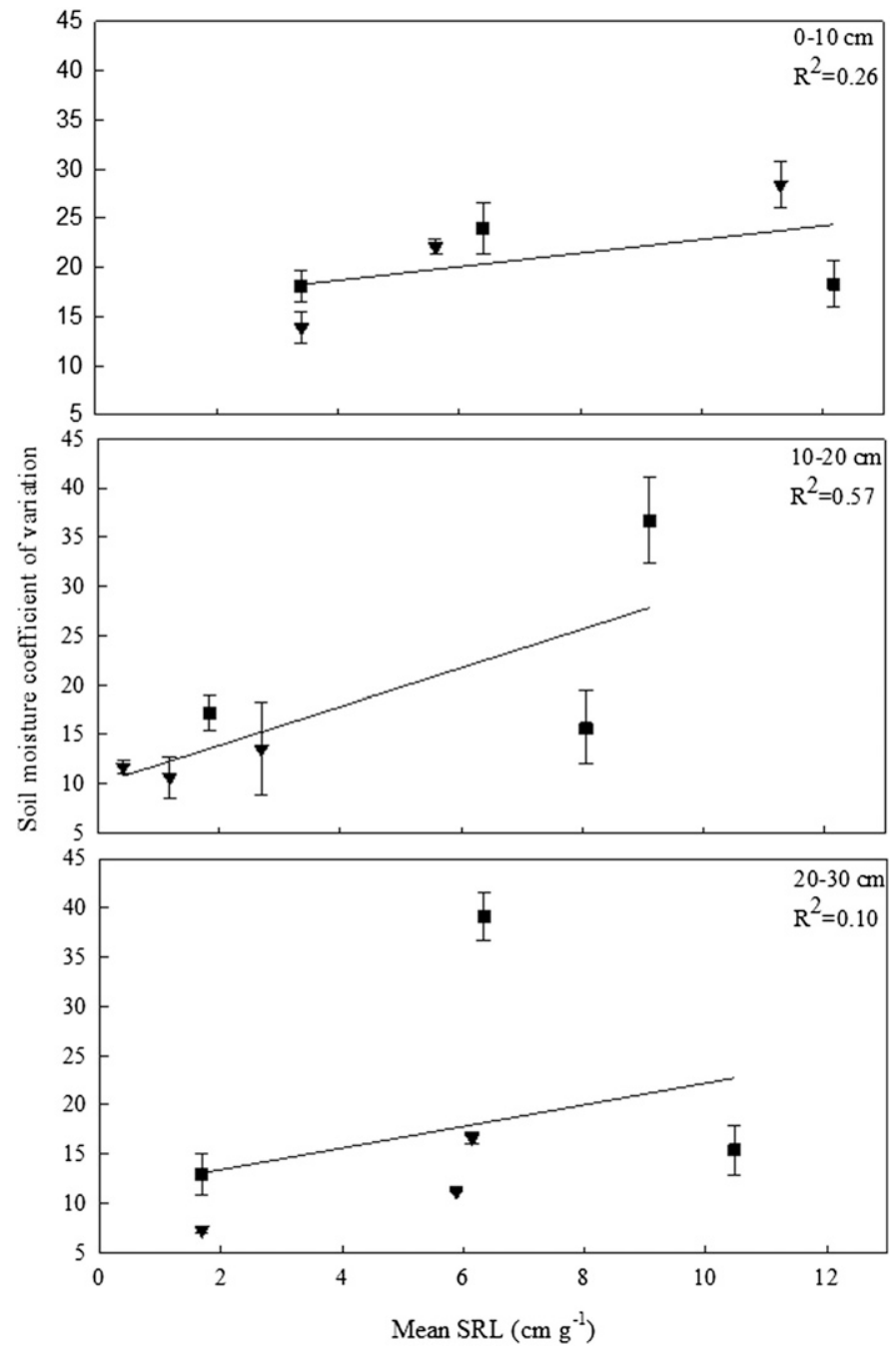

Fig. 3. The relationship of the $\mathrm{CV}$ for volumetric substrate water content in July 2010 to mean specific root length (SRL) over three container depths $(0-10,10-20$, and $20-30 \mathrm{~cm}$ ) for six ornamental tree species (red maple, honey locust, red oak, birch, redbud, and hornbeam $)(n=3$ replicates per tree species $) ; 1 \mathrm{~cm}=0.3937 \mathrm{inch}$, $1 \mathrm{~cm} \cdot \mathrm{g}^{-1}=11.1612 \mathrm{inch} / \mathrm{oz}$.

distribution types nor did they correlate with substrate moisture variability. Our results on SRL suggest that root systems with high SRL (e.g., long and thin roots) may increase substrate moisture variation. These results could largely be driven by the often fast growth rates associated with tree species with high SRL (Comas et al., 2002), resulting in higher variation because of faster root growth. Root systems with high SRL may also come at the cost of a shorter root lifespan, a direct result of less carbon investment in the root tissues (McCormack et al., 2012), which could also result in more rapid root tissue turnover and similarly higher soil moisture variability.

Intensive ornamental tree container production systems stand to benefit from optimal water and fertilizer inputs. Substrate moisture sensors offer a plausible and affordable method to monitor and control irrigation. As a means to effectively reduce the number of substrate moisture sensors required for accurate container VWC estimates, we must first understand the effects of root system growth and distribution on sensor readings and variability. Although root system distribution in the soil profile can have serious consequences on a plant's ability to forage for water and nutrients, deconstructing a containerized root system by root function, as a means to approach the proportion of roots responsible for water uptake vs. transport, has not previously been considered for containerized trees. We found that root system distribution within the container can influence sensor variation based on the location of root biomass density and furthermore that root systems with larger proportions of coarser transport roots and/or woody biomass highly affect sensor variability. Although further testing is clearly warranted, initial results indicate horizontal sensor placement within the center of the container (i.e., inserted through the container wall) results in the least amount of sensor variability in conical rooting systems while cylindrical-rooted species should be examined on an individual basis.

\section{Literature cited}

Andreu, L., J.W. Hopmans, and L.J. Schwankl. 1997. Spatial and temporal distribution of soil water balance for a drip-irrigated almond tree. Agr. Water Mgt. 35:127-146.

Beeson, R.C. 2007. Determining plantavailable water of woody ornamentals in containers in situ during production. HortScience 42:1700-1704.

Berntson, G.M. 1997. Topological scaling and plant root system architecture: Developmental and functional hierarchies. New Phytol. 135:621-634.

Bilderback, T.E. 2002. Water management is key in reducing nutrient runoff 
from container nurseries. HortTechnology 12:7-9.

Cannavo, P. and J.-C. Michel. 2013. Peat particle size effects on spatial root distribution, and changes on hydraulic and aeration properties. Sci. Hort. 151:11-21.

Clothier, B.E. and S.R. Green. 1994. Root zone processes and the efficient use of irrigation water. Agr. Water Mgt. 25: $1-12$.

Coelho, E.F. and D. Or. 1999. Root distribution and water uptake patterns of corn under surface and subsurface drip irrigation. Plant Soil 206:123-136.

Comas, L.H., T.J. Bouma, and D.M. Eissenstat. 2002. Linking root traits to potential growth rate in six temperate tree species. Oecologia 132:34-43.

Daniels, A.B., D.M. Barnard, P.L. Chapman, and W.L. Bauerle. 2012. Optimizing substrate moisture measurements in containerized nurseries. HortScience 47:98-104

Fitter, A. 1987. An architectural approach to the comparative ecology of plant root systems. New Phytol. 106:61-77.

Guo, D., M. Xia, X. Wei, W. Chang, Y. Liu, and Z. Wang. 2008. Anatomical traits associated with absorption and mycorrhizal colonization are linked to root branch order in twenty-three Chinese temperate tree species. New Phytol. 180:673-683.

Hao, X., R. Zhang, and A. Kravchenko. 2005. Effects of root density distribution models on root water uptake and water flow under irrigation. Soil Sci. 170:167174.

Hodge, A. 2004. The plastic plant: Root response to heterogeneous supplies of nutrients. New Phytol. 162:9-24.
Hodge, A., G. Berta, C. Doussan, F. Merchan, and M. Crespi. 2009. Plant root growth, architecture and function. Plant Soil 321:153-187.

McCormack, M.L., T.S. Adams, E.A.H. Smithwick, and D.M. Eissenstat. 2012. Predicting fine root lifespan from plant functional traits in temperate trees. New Phytol. 195:823-831.

Passioura, J.B. 2002. Soil conditions and plant growth. Plant Cell Environ. 25:311-318.

Pregitzer, K.S. 2002. The fine roots of trees: A new perspective. New Phytol. 156:267-270

Yu, G., J. Zhuang, K. Nakayama, and Y. Jan. 2007. Root water uptake and profile soil water as affected by vertical root distribution. Plant Ecol. 189:15-30. 